\title{
Subcostal Transverse Abdominis Plane Block for Acute Pain
}

\section{Management: A Review}

\author{
Jose M Soliz, ${ }^{1, *}$ Ian Lipski, ${ }^{1}$ Shannon Hancher-Hodges, ${ }^{1}$ Barbra Bryce Speer,' and Keyuri Popat ${ }^{1}$ \\ ${ }^{1}$ Department of Anesthesiology and Perioperative Medicine, The University of Texas MD Anderson Cancer Center, Houston, TX, USA \\ "Corresponding author: Jose M Soliz, M.D., Associate Professor, Department of Anesthesiology and Perioperative Medicine, The University of Texas MD Anderson Cancer Center, \\ 1515 Holcombe Blvd.Houston, TX 77030, E-mail: jsoliz@mdanderson.org
}

Received 2017 April 20; Revised 2017 May 09; Accepted 2017 October 10.

\begin{abstract}
The subcostal transverse abdominis plane (SCTAP) block is the deposition of local anesthetic in the transverse abdominis plane inferior and parallel to the costal margin. There is a growing consensus that the SCTAP block provides better analgesia for upper abdominal incisions than the traditional transverse abdominis plane block. In addition, when used as part of a four-quadrant transverse abdominis plane block, the SCTAP block may provide adequate analgesia for major abdominal surgery. The purpose of this review is to discuss the SCTAP block, including its indications, technique, local anesthetic solutions, and outcomes.
\end{abstract}

Keywords: TAP Block, Subcostal TAP Block, Acute Pain, Four Point, Four Quadrant

\section{Introduction}

Traditionally, opioids have been used to manage postoperative pain $(1,2)$. However, an increasing awareness of opioid-related adverse events, including respiratory depression, paralytic ileus, and sedation, has led to a shift towards utilizing opioid-sparing techniques for postoperative analgesia (3-5). As such, outcomes associated with the transverse abdominis plane (TAP) block are of increasing interest $(6,7)$.

The TAP block involves blocking the abdominal wall's sensory innervation, which arises from the anterior division of the thoracolumbar spinal nerves (8). These sensory nerves are in the plane between the internal oblique and transverse abdominis muscles (9). Traditionally, the posterior TAP block is performed at the triangle of Petit. However, the anatomy in the area of the triangle of Petit may vary. In a cadaveric study, Jankovic et al. found that not all cadavers had nerves that entered the TAP at the triangle of Petit but all cadavers had nerves that entered the TAP at the mid-axillary line (10). Therefore, the lateral TAP block performed at the mid-axillary line may provide a better sensory blockade. The benefits of the TAP block have been well documented in randomized controlled trials and metaanalyses (11-15). However, the benefits of the subcostal TAP (SCTAP) block the deposition of local anesthetic in the TAP inferior and parallel to the costal margin (16) have not been as extensively reviewed.

The ultrasound-guided oblique SCTAP block, first described by Hebbard et al., has the potential to provide analgesia for both upper and lower abdominal surgery (17).
There is a growing consensus that the SCTAP block provides better analgesia for upper abdominal incisions than the lateral TAP block (18). The purpose of this review is to discuss the SCTAP block, including its indications, technique, local anesthetics, and clinical outcomes.

\section{Indications}

The posterior TAP block has been found to provide consistent blockade of the T10-L1 abdominal dermatomes. The resulting infraumbilical blockade works well for lower abdominal surgery involving a Pfannenstiel incision, such as cesarean section, hysterectomy, prostatectomy, or laparoscopic hand-assisted surgery (8). However, many abdominal surgeries involve an open approach with a vertical midline incision that extends above the umbilical area. In these situations, the SCTAP block may be used to extend the sensory blockade to the T7 abdominal dermatomes.

Epidural analgesia is considered the gold standard for pain management after abdominal surgery (19). In some cases, however, potential complications, adverse events, and the need for active postoperative management make the use of epidural analgesia undesirable $(20,21)$. The TAP block via various approaches provides some advantages over neuraxial anesthesia. For example, TAP blocks are associated with a lower use of intraoperative phenylephrine and a lesser degree of intraoperative blood pressure changes (22). The SCTAP block may be utilized in cases in which neuraxial anesthesia is contraindicated, such as patients with coagulation issues or infection at the epidural puncture site. Although the SCTAP block provides sen- 
sory blockade of the abdominal wall, it is lacking in coverage of visceral pain (23). The lack of visceral pain analgesia may require the use of additional methods of postoperative pain control such as intravenous opioids or nonnarcotic analgesics.

\section{Technique}

\subsection{Patient Positioning}

ASCTAP block may be performed on an anesthetized or conscious patient. The patient is supine; if only the SCTAP block will be performed, arm extension is not necessary to adequately perform ultrasound imaging over the subcostal area of the abdomen. However, if a lateral TAP block will be performed in addition to the SCTAP block, the patient's arm is extended away from the operating table (Figure 1) for adequate exposure.

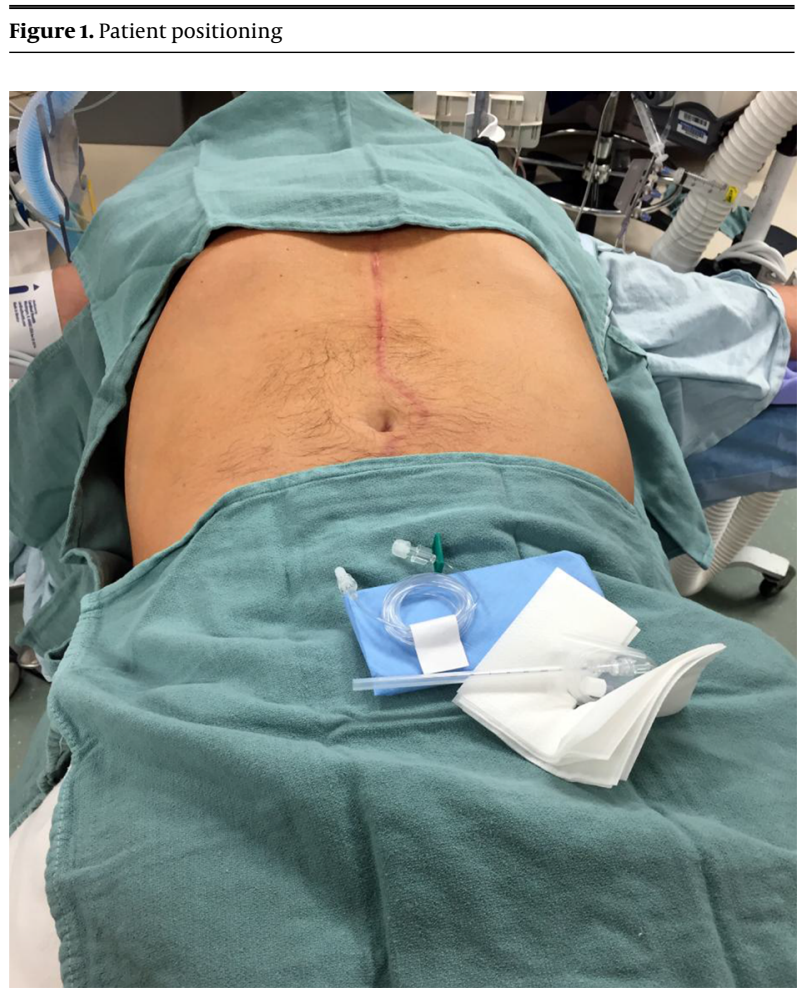

Patient is supine with arms extended allowing access to SCTAP and lateral TAP approaches.

SCTAP blocks can be performed preoperatively in the holding area, after anesthesia induction in the operating room, or postoperatively in the recovery room or hospital ward. The challenge of performing the SCTAP block postoperatively is the distortion of the abdominal musculature caused by surgery, which can distort the ultrasound image.
The ultrasound image depends on the shape of the probe and the frequency used. Modern probes use a wide bandwidth. For SCTAP blocks, a linear array probe employing 5 $-15 \mathrm{MHz}$ is typically used. Because the SCTAP block is a relatively superficial block, a small-bore blunt tip needle, such as a $22 \mathrm{G}$ Tuohy needle, would be adequately visualized on ultrasonography. Regional block needles with echogenic tips also facilitate ultrasound-guided imaging.

\subsection{Ultrasound Visualization and Local Anesthetic Injection}

A sterile, sheathed linear ultrasound probe is initially placed below the xyphoid process to view the linea alba (Figure 2). The probe is then directed obliquely down the costal margin while keeping the rectus abdominis muscle in view. The transverse abdominis muscle come into view below the rectus abdominis muscle (Figure 3 ). The probe is advanced further until the semilunaris is viewed. Figure 4 shows an ultrasound image of the semilunaris with the rectus abdominis, transverse abdominis, interior oblique, and external oblique muscles in view. An echogenic needle is inserted in-plane (Figure 5) until the needle tip reaches the fascia between the rectus abdominis and the transverse abdominis muscles.

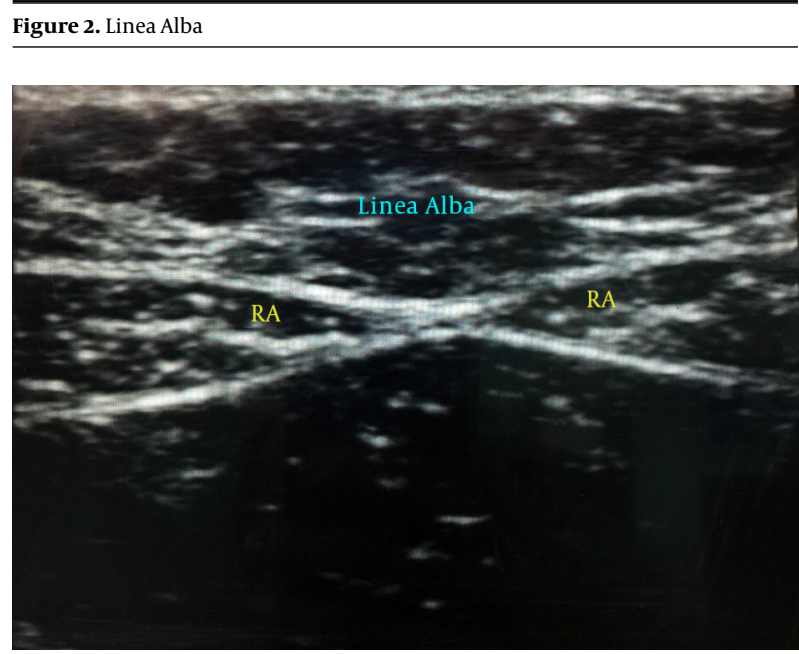

The linea alba is first viewed while placing the ultrasound below the xyphoid process. Bilateral rectus abdominis (RA) muscles are viewed.

Anatomic variations of nerve entry into the rectus abdominis muscle make local anesthetic volume a key component of the block. Local anesthetic may be injected into the TAP plane medial or lateral to the semilunaris. An injection medial to the semilunaris may miss nerves that enter the rectus abdominis muscle lateral to the injection site. However, a medial injection may provide a higher spread of local anesthetic. Once the needle enters the TAP 


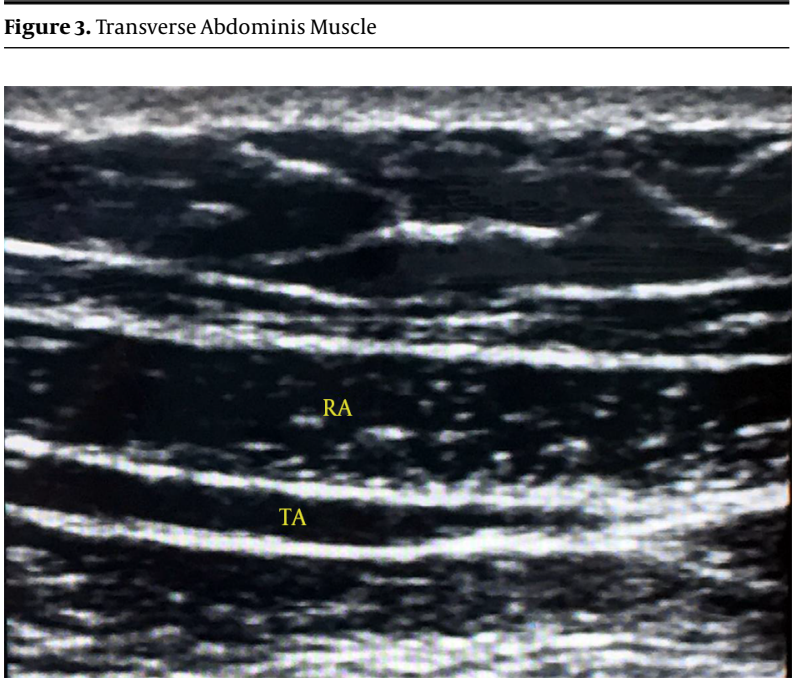

As the ultrasound is directed down the costal margin, the transverse abdominis (TA) muscle comes into view. RA, rectus abdominis.

Figure 4. Ultrasound Image At the Semilunaris

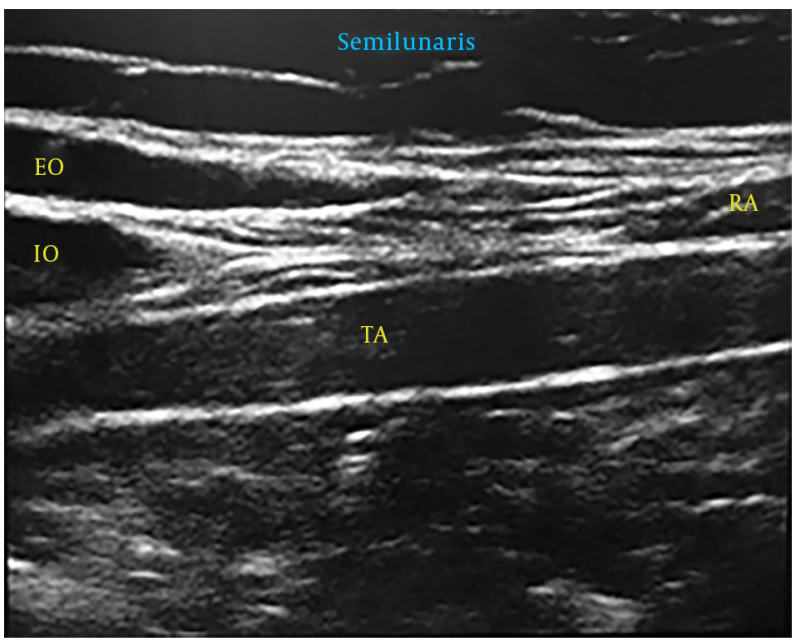

EO, external oblique muscle; IO, internal oblique muscle; TA, transverse abdominis muscle; RA, rectus abdominis muscle.

plane, 1 - $2 \mathrm{~mL}$ of saline may be injected to confirm needle tip placement. Local anesthetic injection is performed using 15 - $20 \mathrm{cc}$ of local anesthetic per injection site bilaterally (Figure 6). Through a single subcostal injection, the SCTAP block can potentially cover dermatomal levels T7T10, although the lateral cutaneous branches of the segmental nerves are not blocked $(24,25)$. Hence, the SCTAP block may not adequately cover areas lateral to the midclavicular lines where drains or ports may be placed. Similar to an epidural analgesia dermatome assessment, the re-

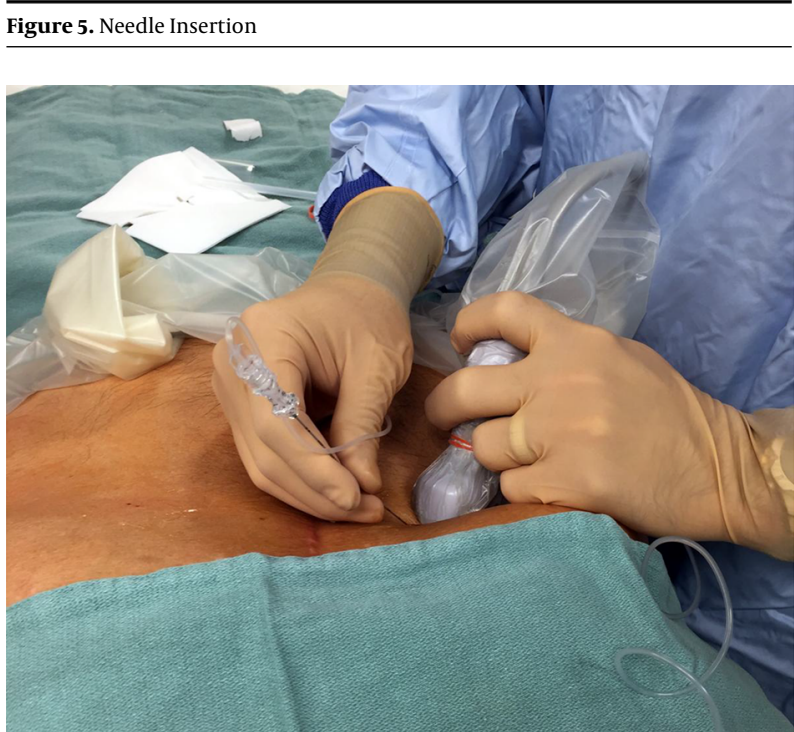

The needle is inserted in-plane to the ultrasound probe. The proceduralist stands on the contralateral side facing the ultrasound.

sulting sensory block may be adequately tested with both cold and pinprick sensory examinations (26).

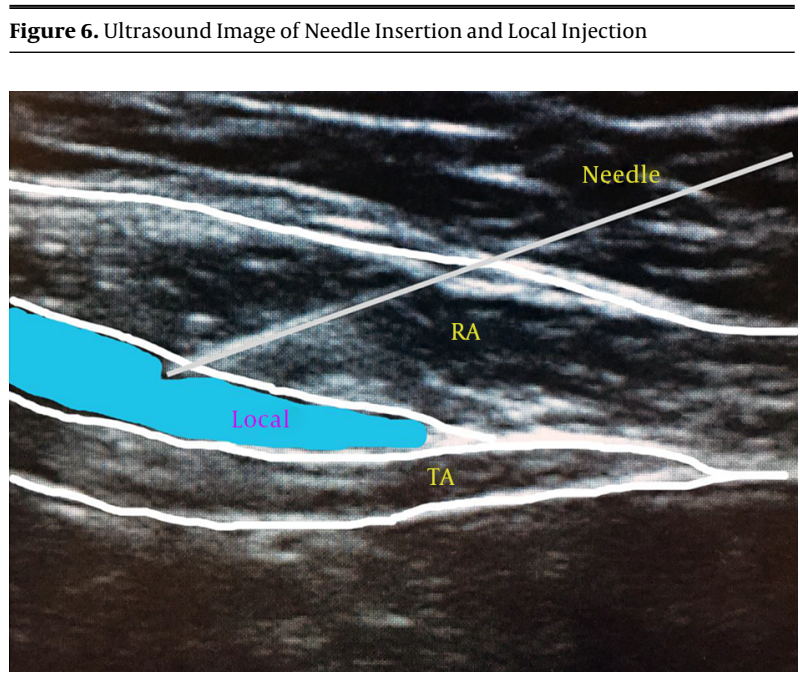

TA, transverse abdominis muscle; RA, rectus abdominis muscle. The needle is inserted in the fascial plane between the TA muscle and RA muscle. As shown in this image, local anesthetic injection should cause separation of TA and RA muscles. The injection is medial to the semilunaris in this image.

Once the needle enters the TAP plane, a dynamic injection can be performed by advancing the needle under ultrasound guidance laterally in the pocket created by the initial injection of $5-10 \mathrm{~mL}$ of local anesthetic; as the needle is advanced, the remaining local anesthetic is injected (Figure 7). This allows for a more lateral spread of the lo- 
cal anesthetic (27). Alternatively, the needle could be advanced laterally and then medially while anesthetic is injected to account for anatomical variation and achieve adequate coverage. The injection starts at the mid-axillary line in this approach, which may be ideal for continuous catheter placement (28).

\subsection{Four-Quadrant TAP Block}

For the four-quadrant TAP (4QTAP) block (also known as the 4-point TAP block), the patient is supine with the arms extended. The ultrasound machine and the proceduralist are positioned on opposite sides of the operation table. Without moving to a different position, the proceduralist performs the ultrasonography and anesthetic injection for the contralateral lateral TAP block first, the contralateral SCTAP block second, the ipsilateral SCTAP third, and the ipsilateral lateral TAP block fourth. In this manner, both the ultrasound machine and the proceduralist may remain stationary while the entire 4 QTAP block is performed.

\section{Local Anesthetic Solutions}

Local anesthetics are the primary choice of analgesic agent for the SCTAP block. Agents such as liposomal bupivacaine, opioids, vasoconstricting agents, and other adjuncts have been used with local anesthetics for TAP blocks (29-31). The choice of injectate depends on patient factors, the surgery type, and the proceduralist's discretion.

\subsection{Local Anesthetics}

Local anesthetics are the most commonly used agents for the SCTAP block. Amide-type local anesthetics such as lidocaine, bupivacaine, and ropivacaine are widely used, as the duration of their action may approach $6-8$ hours without the use of adjuncts.

Bilateral SCTAP requires the blockade of multiple sensory nerves and thus the use of high volumes of local anesthetics. Dosing strategies are of the utmost importance when using local anesthetics, as local anesthetic toxicity is possible when more than the maximum recommended dose is used. Compared with bolus dosing alone, bolus dosing plus continuous infusion may increase the plasma concentrations of local anesthetics (32). Mild toxicity from local anesthetics has been reported in multiple patients undergoing TAP blocks for cesarean section analgesia, so caution should be used in this patient population (33).

The use of $15 \mathrm{~mL}$ to $20 \mathrm{~mL}$ of local anesthetic at each injection site provides enough volume for local anesthetic spread (9). In a cadaver study employing injections of equal volumes of anesthetic for TAP block, the subcostal approach resulted in a larger area of coverage than the mid-axillary or lumbar triangle of Petit approaches (34). In another study, $20 \mathrm{~mL}$ of ropivacaine $0.5 \%$ was injected bilaterally into the subcostal region. The spread of sensory change to dermatomes T5-L3 was highly variable; however, all patients had a T10-T12 dermatomal block after 30 minutes (24). In general, when selecting a type, concentration, and volume of local anesthetic, care should be taken to stay within the therapeutic dose range to avoid high plasma concentrations.

\subsection{Liposomal Bupivacaine}

Interest in the co-administration of liposomal bupivacaine with bupivacaine has increased since the U.S. Food and drug administration approved liposomal bupivacaine in 2015. At dosing ratios of greater than 2:1, liposomal bupivacaine and bupivacaine may be co-administered through a single injection. At ratios of 2:1 or smaller, the substantial displacement of free bupivacaine from the liposomes may occur (35). Kharitonov reported that the use of liposomal bupivacaine with epinephrine, corticosteroids, and/or opioids was not associated with adverse events (35).

The injection of liposomal bupivacaine for postoperative analgesia is now used for TAP blocks. The longer duration of analgesia achieved with the use of liposomal bupivacaine presents some advantages over traditional local anesthetics. Several studies suggest that liposomal bupivacaine has benefits over bupivacaine alone for SCTAP blocks (29). In one randomized prospective trial in patients who received SCTAP block for robotic hysterectomy, Hutchins et al. found that patients who received liposomal bupivacaine had lower opioid requirements for the first 72 hours after surgery and had lower pain scores than those who received bupivacaine (36).

\subsection{Combinations and Adjuncts}

When selecting a local anesthetic for SCTAP blocks, most practitioners select those that are longer acting, such as ropivacaine, bupivacaine, or liposomal bupivacaine. Typically, these local anesthetics are considered because of their longer-lasting effects and the fact that most SCTAP blocks are used primarily for postoperative analgesia or as part of multimodal analgesia, not as the sole means of intraoperative anesthesia (37). As with any regional analgesia technique, the onset, density, and duration of the SCTAP block can be optimized with certain combinations of local anesthetics and adjuvants (38).

Several studies have documented the benefits of combining anesthetics for SCTAP blocks. In one study, patients with TAP blocks with local anesthesia (liposomal bupivacaine $1.3 \%$ diluted to $20 \mathrm{~mL}$ in addition to $10 \mathrm{~mL}$ of bupi- 


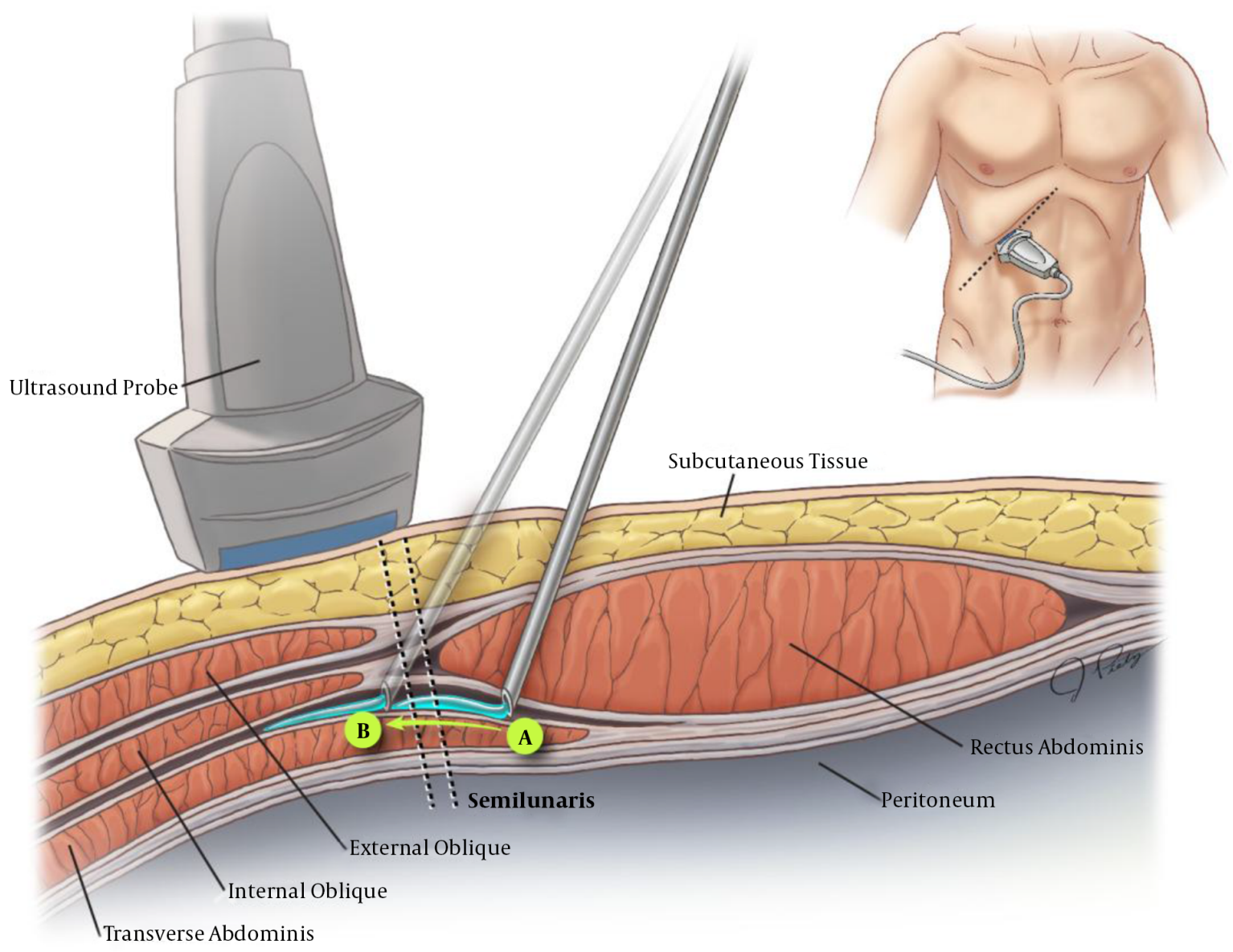

Visual Art: () 2016 The University of Texas MD Anderson Cancer Center

The TAP plane is entered with the needle. While local anesthetic is injected, the needle is advanced laterally resulting in lateral spread of the local anesthetic.

vacaine $0.25 \%$ with 1:200,000 epinephrine at each injection site) had shorter hospital stays than patients without TAP blocks did (29). In another study in patients undergoing cesarean sections, the addition of $8 \mathrm{mg}$ of dexamethasone to the local anesthetic (levobupivacaine $0.25 \%$ ) for a TAP block prolonged the time between requests for postoperative analgesia (39). However, in a different study of 66 cholecystectomy patients, dexamethasone had no additive or synergistic effects on the SCTAP block with respect to analgesia efficacy (40).

Combining anesthetics and/or using adjuncts for SCTAP blocks do not always convey a benefit. In one study, sufentanil was added to a bupivacaine TAP block; however, this addition did nothing to reduce patients' pain intensity or requests for intravenous fentanyl in the recovery room (31). Similarly, the addition of clonidine to bupivacaine TAP blocks did nothing to improve the short- or longterm pain scores of patients who had undergone cesarean section (41). When combining local anesthetics and/or adjuncts, care should be taken to select the appropriate combinations that will maximize analgesic effects while minimizing any potential side effects or complications (42).

\section{Complications}

Similar to the posterior and lateral TAP block, the SCTAP block has a low risk for serious complications owing to the increased safety of ultrasound-guided needle placement and 'real-time' visualization through dynamic scanning, (43). Needle puncture of the peritoneum causing bowel 
or diaphragm perforation is unlikely but still a possibility. Given the abundance of structures in the peritoneal cavity, the needle in-plane must be viewed at all times during needle advancement. Lacerations of the liver during the placement of right-sided TAP blocks have been reported (44). Abdominal wall hematoma, vascular injury, and local anesthetic toxicity are also potential but rare complications (14).

Reports of local anesthetic toxicity with TAP blocks are rare. However, such toxicity can occur, as large volumes of local anesthetic are routinely used (45). In fact, one study demonstrated that ropivacaine $(3 \mathrm{mg} / \mathrm{kg}$ ) given during a SCTAP block resulted in rapid increases in plasma concentrations of the local anesthetic during the first 2 hours after the block was performed (45). Staying below the maximum recommended dosing when administering local anesthetics is of the utmost importance.

In the past 30 years, the incidence of systemic toxicity from local anesthetics has decreased significantly. Peripheral nerve blocks are associated with the lowest incidence of serious nerve injury but the highest incidence of systemic toxicity; thus, all candidates for regional anesthesia with a SCTAP block should be thoroughly evaluated and informed of all possible complications and side effects (46). As with all regional techniques, patients receiving SCTAP blocks should be fully monitored and given supplemental oxygen during block placement. Frequent aspiration and slow, fractionated injections of local anesthetic solution with or without adjuncts should be routine. A 20\% intravenous fat emulsion (e.g., INTRALIPID) should be readily available and given promptly if signs and/or symptoms of local anesthetic toxicity are observed (47).

\section{Perioperative Outcomes}

As of the writing of this manuscript, no meta-analysis of SCTAP block use has been performed. However, several randomized controlled trials support the use of SCTAP blocks, particularly when compared to patient-controlled intravenous analgesia with or without local injection at the surgical site $(27,48,49)$. The results of studies comparing the SCTAP block to epidural analgesia have been inconsistent $(50,51)$. For example, Niraj et al. found that although the postoperative pain scores during coughing of patients who underwent abdominal surgery with a TAP block and those who underwent surgery with an epidural did not differ at 8 hours, patients with a TAP block did required more tramadol for pain control (52).

The SCTAP block has been compared to the posterior TAP block for various surgery types. In general, patients who have surgical incisions above the umbilicus have better pain control with a SCTAP block than with a posterior
TAP block. Likewise, in a study comparing sensory examinations, the SCTAP block provided a better dermatomal block in the upper abdomen than the posterior TAP block (53). In a randomized trial of patients undergoing laparoscopic cholecystectomy, patients who received SCTAP blocks had less pain at rest and during movement than patients who received posterior TAP blocks did (54). A study by Shin et al. provided similar results for patients undergoing laparoscopic cholecystectomy (55).

In a cadaveric study, the 4QTAP block adequately covered dermatomes T8-L1. Compared with the SCTAP alone, the 4QTAP block may be more beneficial in patients undergoing major abdominal surgery (56). In a prospective study of 124 patients, the incision for abdominal surgery was within the dermatomal limits of the 4QTAP block in $70 \%$ of patients (43). In a later study of patients undergoing laparoscopic colorectal surgery, Niraj et al. demonstrated that the 4QTAP block with levobupivacaine resulted in pain scores and tramadol consumption similar to those achieved with epidural analgesia (52).

Although epidural analgesia has been shown to improve postoperative respiratory function, data regarding respiratory function with the use of the TAP block are conflicting (57). In a double-blind randomized control trial, Basaran et al. found that the SCTAP block improved respiratory function following laparoscopic cholecystectomy (58).

\section{Summary}

Although it does not provide visceral analgesia and is subject to anatomical differences in abdominal wall sensory nerve distribution, the SCTAP block shows promise as a valuable tool in acute pain management and as a component of multimodal approaches to analgesia. The block has been shown to provide excellent pain relief in patients undergoing upper abdominal surgery and, when used as part of a 4QTAP block, the SCTAP block may provide adequate analgesia for major abdominal surgery. When used with liposomal bupivacaine with or without the coadministration of standard bupivacaine or other adjuncts, the SCTAP block shows the potential to prolong analgesia through a bilateral, single-injection technique or thru the use of continuous catheters. Further prospective studies of the SCTAP block may provide valuable insight on optimal local anesthetic preparations, the injection of local anesthetics medial or lateral to the semilunaris, the use of the 4QTAP block, and the effect on postoperative complications. 


\section{Footnotes}

Conflicts of Interests: The authors have no conflicts of interests to declare.

\section{Funding/Support: None.}

\section{References}

1. Kalkman CJ, Visser K, Moen J, Bonsel GJ, Grobbee DE, Moons KG. Preoperative prediction of severe postoperative pain. Pain. 2003;105(3):41523. doi: 10.1016/S0304-3959(03)00252-5. [PubMed: 14527702].

2. Funk RD, Hilliard P, Ramachandran SK. Perioperative opioid usage: avoiding adverse effects. Plast Reconstr Surg. 2014;134(4 Suppl 2):32S9S. doi: 10.1097/PRS.0000000000000680. [PubMed: 25255004].

3. Zhao SZ, Chung F, Hanna DB, Raymundo AL, Cheung RY, Chen C. Doseresponse relationship between opioid use and adverse effects after ambulatory surgery. J Pain Symptom Manage. 2004;28(1):35-46. doi: 10.1016/j.jpainsymman.2003.11.001. [PubMed: 15223083].

4. Oderda GM, Said Q, Evans RS, Stoddard GJ, Lloyd J, Jackson K, et al. Opioid-related adverse drug events in surgical hospitalizations: impact on costs and length of stay. Ann Pharmacother. 2007;41(3):400-6. doi: 10.1345/aph.1H386. [PubMed: 17341537].

5. Pizzi LT, Toner R, Foley K, Thomson E, Chow W, Kim M, et al. Relationship between potential opioid-related adverse effects and hospital length of stay in patients receiving opioids after orthopedic surgery. Pharmacotherapy. 2012;32(6):502-14. doi: 10.1002/j.18759114.2012.01101.x. [PubMed: 22570188].

6. Baeriswyl M, Kirkham KR, Kern C, Albrecht E. The Analgesic Efficacy of Ultrasound-Guided Transversus Abdominis Plane Block in Adult Patients: A Meta-Analysis. Anesth Analg. 2015;121(6):1640-54. doi: 10.1213/ANE.0000000000000967. [PubMed: 26397443].

7. De Oliveira GJ, Castro-Alves LJ, Nader A, Kendall MC, McCarthy RJ. Transversus abdominis plane block to ameliorate postoperative pain outcomes after laparoscopic surgery: a meta-analysis of randomized controlled trials. Anesth Analg. 2014;118(2):454-63. doi: 10.1213/ANE.0000000000000066. [PubMed: 24445643].

8. Young MJ, Gorlin AW, Modest VE, Quraishi SA. Clinical implications of the transversus abdominis plane block in adults. Anesthesiol Res Pract. 2012;2012:731645. doi: 10.1155/2012/731645. [PubMed: 22312327].

9. Mukhtar K, Singh S. Ultrasound-guided transversus abdominis plane block. Br J Anaesth. 2009;103(6):900. doi: 10.1093/bja/aep323. [PubMed: 19918027] author reply 900-1.

10. Jankovic ZB, du Feu FM, McConnell P. An anatomical study of the transversus abdominis plane block: location of the lumbar triangle of Petit and adjacent nerves. Anesth Analg. 2009;109(3):981-5. doi: 10.1213/ane.0b013e3181ae0989. [PubMed:19690277].

11. Petersen PL, Mathiesen O, Torup H, Dahl JB. The transversus abdominis plane block: a valuable option for postoperative analgesia? A topical review. Acta Anaesthesiol Scand. 2010;54(5):529-35. doi: 10.1111/j.1399-6576.2010.02215.x. [PubMed: 20175754].

12. Ra YS, Kim CH, Lee GY, Han JI. The analgesic effect of the ultrasoundguided transverse abdominis plane block after laparoscopic cholecystectomy. Korean J Anesthesiol. 2010;58(4):362-8. doi: 10.4097/kjae.2010.58.4.362. [PubMed: 20508793].

13. Serag Eldin M, Mahmoud F, El Hassan R, Abdel Raouf M, Afifi MH, Yassen $\mathrm{K}$, et al. Intravenous patient-controlled fentanyl with and without transversus abdominis plane block in cirrhotic patients post liver resection. Local Reg Anesth. 2014;7:27-37. doi:10.2147/LRA.S60966. [PubMed: 24971036].

14. Yu N, Long X, Lujan-Hernandez JR, Succar J, Xin X, Wang X. Transversus abdominis-plane block versus local anesthetic wound infiltration in lower abdominal surgery: a systematic review and meta-analysis of randomized controlled trials. BMC Anesthesiol. 2014;14:121. doi: 10.1186/1471-2253-14-121. [PubMed: 25580086].
15. Abdallah FW, Laffey JG, Halpern SH, Brull R. Duration of analgesic effectiveness after the posterior and lateral transversus abdominis plane block techniques for transverse lower abdominal incisions: a meta-analysis. Br J Anaesth. 2013;111(5):721-35. doi: 10.1093/bja/aet214. [PubMed: 23811424].

16. Mukherjee A, Guhabiswas R, Kshirsagar S, Rupert E. Ultrasound guided oblique subcostal transversus abdominis plane block: An observational study on a new and promising analgesic technique. Indian J Anaesth. 2016;60(4):284-6. doi: 10.4103/0019-5049.179468. [PubMed: 27141114].

17. Hebbard PD, Barrington MJ, Vasey C. Ultrasound-guided continuous oblique subcostal transversus abdominis plane blockade: description of anatomy and clinical technique. Reg Anesth Pain Med. 2010;35(5):436-41. doi: 10.1097/AAP.ob013e3181e66702. [PubMed: 20830871].

18. Oksar M, Koyuncu O, Turhanoglu S, Temiz M, Oran MC. Transversus abdominis plane block as a component of multimodal analgesia for laparoscopic cholecystectomy. J Clin Anesth. 2016;34:72-8. doi: 10.1016/j.jclinane.2016.03.033. [PubMed: 27687350].

19. Popping DM, Elia N, Van Aken HK, Marret E, Schug SA, Kranke $P$, et al. Impact of epidural analgesia on mortality and morbidity after surgery: systematic review and meta-analysis of randomized controlled trials. Ann Surg. 2014;259(6):1056-67. doi: 10.1097/SLA.0000000000000237. [PubMed: 24096762].

20. Rawal N. Epidural technique for postoperative pain: gold standard no more? Reg Anesth Pain Med. 2012;37(3):310-7. doi: 10.1097/AAP.0b013e31825735c6. [PubMed: 22531384].

21. Wildsmith JA. Continuous thoracic epidural block for surgery: gold standard or debased currency? Br J Anaesth. 2012;109(1):9-12. doi: 10.1093/bja/aes177. [PubMed: 22696554].

22. Furuya A, Ikemoto K, Asano N, Tamaki F, Suzuki S, Nonaka A. [Assessment of intraoperative hemodynamics, infusion volume, urinary output and dose of circulatory drugs in general anesthesia with transversus abdominis plane block for cholecystectomy]. Masui. 2013;62(9):1106-11. [PubMed: 24063137].

23. Lissauer J, Mancuso K, Merritt C, Prabhakar A, Kaye AD, Urman RD. Evolution of the transversus abdominis plane block and its role in postoperative analgesia. Best Pract Res Clin Anaesthesiol. 2014;28(2):117-26. doi: 10.1016/j.bpa.2014.04.001. [PubMed: 24993433].

24. Barrington MJ, Ivanusic JJ, Rozen WM, Hebbard P. Spread of injectate after ultrasound-guided subcostal transversus abdominis plane block: a cadaveric study. Anaesthesia. 2009;64(7):745-50. doi: 10.1111/j.1365-2044.2009.05933.x. [PubMed: 19624629].

25. Sondekoppam RV, Brookes J, Morris L, Johnson M, Ganapathy S. Injectate spread following ultrasound-guided lateral to medial approach for dual transversus abdominis plane blocks. Acta Anaesthesiol Scand. 2015;59(3):369-76. doi: 10.1111/aas.12459. [PubMed: 25582299].

26. Mitchell AU, Torup H, Hansen EG, Petersen PL, Mathiesen O, Dahl JB, et al. Effective dermatomal blockade after subcostal transversus abdominis plane block. Dan Med J. 2012;59(3):A4404. [PubMed: 22381092].

27. Li K, Li L, Gao M, Zhu Z, Chen P, Yang L, et al. Application of ultrasound-guided subcostal transversus abdominis plane block in gastric cancer patients undergoing open gastrectomy. Int J Clin Exp Med. 2015;8(8):13976-82. [PubMed: 26550355].

28. Ganapathy S, Sondekoppam RV, Terlecki M, Brookes J, Das Adhikary S, Subramanian L. Comparison of efficacy and safety of lateral-to-medial continuous transversus abdominis plane block with thoracic epidural analgesia in patients undergoing abdominal surgery: A randomised, open-label feasibility study. EurJ Anaesthesiol. 2015;32(11):797-804. doi: 10.1097/EJA.0000000000000345. [PubMed: 26426576].

29. Hutchins J, Vogel RI, Ghebre R, McNally A, Downs LJ, Gryzmala E, et al. Ultrasound-guided subcostal transversus abdominis plane infiltration with liposomal bupivacaine for patients undergoing roboticassisted hysterectomy: a retrospective study. Int J Gynecol Cancer. 
2015;25(5):937-41. doi: 10.1097/IGC.0000000000000429. [PubMed: 25790044].

30. Restrepo-Garces CE, Asenjo JF, Gomez CM, Jaramillo S, Acosta N, Ramirez LJ, et al. Subcostal transversus abdominis plane phenol injection for abdominal wall cancer pain. Pain Pract. 2014;14(3):278-82. doi:10.1111/papr.12065. [PubMed: 23560547].

31. Saliminia A, Azimaraghi O, Babayipour S, Ardavan K, Movafegh A. Efficacy of transverse abdominis plane block in reduction of postoperation pain in laparoscopic cholecystectomy. Acta Anaesthesiol Taiwan. 2015;53(4):119-22. doi: 10.1016/j.aat.2015.07.003. [PubMed: 26282913].

32. Hessian EC, Evans BE, Woods JA, Taylor DJ, Kinkel E, Bjorksten AR. Plasma ropivacaine concentrations during bilateral transversus abdominis plane infusions. Br J Anaesth. 2013;111(3):488-95. doi: 10.1093/bja/aet065. [PubMed: 23562932].

33. Griffiths JD, Le NV, Grant S, Bjorksten A, Hebbard P, Royse C. Symptomatic local anaesthetic toxicity and plasma ropivacaine concentrations after transversus abdominis plane block for Caesarean section. Br J Anaesth. 2013;110(6):996-1000. doi: 10.1093/bja/aet015. [PubMed: 23454825].

34. Milan Z, Tabor D, McConnell P, Pickering J, Kocarev M, du Feu F, et al. Three different approaches to Transversus abdominis planeblock: a cadaveric study. Med Glas (Zenica). 2011;8(2):181-4. [PubMed: 21849936].

35. Kharitonov V. A review of the compatibility of liposome bupivacaine with other drug products and commonly used implant materials. Postgrad Med. 2014;126(1):129-38. doi: 10.3810/pgm.2014.01.2733. [PubMed: 24393760].

36. Hutchins J, Delaney D, Vogel RI, Ghebre RG, Downs LJ, Carson L, et al. Ultrasound guided subcostal transversus abdominis plane(TAP) infiltration with liposomal bupivacaine for patients undergoing robotic assisted hysterectomy: A prospective randomized controlled study. Gynecol Oncol. 2015;138(3):609-13. doi: 10.1016/j.ygyno.2015.06.008. [PubMed: 26056753].

37. Bonnet F, Berger J, Aveline C. Transversus abdominis plane block: what is its role in postoperative analgesia? Br J Anaesth. 2009;103(4):468-70. doi: 10.1093/bja/aep243. [PubMed: 19749115].

38. Brummett CM, Williams BA. Additives to local anesthetics for peripheral nerve blockade. Int Anesthesiol Clin. 2011;49(4):104-16. doi: 10.1097/AIA.ob013e31820e4a49. [PubMed: 21956081].

39. Akkaya A, Yildiz I, Tekelioglu UY, Demirhan A, Bayir H, Ozlu T, et al. Dexamethasone added to levobupivacaine in ultrasound-guided tranversus abdominis plain block increased the duration of postoperative analgesia after caesarean section: a randomized, double blind, controlled trial. Eur Rev Med Pharmacol Sci. 2014;18(5):717-22. [PubMed: 24668714].

40. Huang SH, Lu J, Gan HY, Li Y, Peng YG, Wang SK. Perineural dexamethasone does not enhance the analgesic efficacy of ultrasound-guided subcostal transversus abdominis plane block during laparoscopic cholecystectomy. Hepatobiliary Pancreat Dis Int. 2016;15(5):540-5. doi: 10.1016/S1499-3872(16)60086-3. [PubMed: 27733325].

41. Bollag L, Richebe P, Siaulys M, Ortner CM, Gofeld M, Landau R. Effect of transversus abdominis plane block with and without clonidine on post-cesarean delivery wound hyperalgesia and pain. Reg Anesth Pain Med. 2012;37(5):508-14. doi: 10.1097|AAP.ob013e318259ce35. [PubMed: 22683707].

42. Bailard NS, Ortiz J, Flores RA. Additives to local anesthetics for peripheral nerve blocks: Evidence, limitations, and recommendations. Am J Health Syst Pharm. 2014;71(5):373-85. doi: 10.2146/ajhp130336. [PubMed: 24534592].

43. Niraj G, Kelkar A, Hart E, Kaushik V, Fleet D, Jameson J. Four quadrant transversus abdominis plane block and continuous transversus abdominis plane analgesia: a 3-year prospective audit in 124 patients. J Clin Anesth. 2015;27(7):579-84. doi: 10.1016/j.jclinane.2015.07.005. [PubMed: 26319886].

44. Lancaster P, Chadwick M. Liver trauma secondary to ultrasoundguided transversus abdominis plane block. $\mathrm{Br} J$ Anaesth.
2010;104(4):509-10. doi: 10.1093/bja/aeq046. [PubMed: 20228188]

45. Toju K, Shiraishi K, Hakozaki T, Isosu T, Murakawa M. Plasma ropivacaine concentration following ultrasound-guided subcostal transversus abdominis plane block in adults. J Anesth. 2015;29(1):1468. doi: 10.1007/s00540-014-1864-0. [PubMed: 24935748].

46. Cox B, Durieux ME, Marcus MA. Toxicity of local anaesthetics. Best Pract Res Clin Anaesthesiol. 2003;17(1):111-36. doi 10.1053/bean.2003.0275. [PubMed:12751552].

47. Neal JM, Bernards CM, Butterworth J, Di Gregorio G, Drasner $\mathrm{K}$, Hejtmanek MR, et al. ASRA practice advisory on local anesthetic systemic toxicity. Reg Anesth Pain Med. 2010;35(2):152-61. doi: 10.1097/AAP.ob013e3181d22fcd. [PubMed: 20216033].

48. Milan ZB, Duncan B, Rewari V, Kocarev M, Collin R. Subcostal transversus abdominis plane block for postoperative analgesia in liver transplant recipients. Transplant Proc. 2011;43(7):2687-90. doi: 10.1016/j.transproceed.2011.06.059. [PubMed: 21911147].

49. Tolchard S, Davies R, Martindale S. Efficacy of the subcostal transversus abdominis plane block in laparoscopic cholecystectomy: Comparison with conventional port-site infiltration. J Anaesthesiol Clin Pharmacol. 2012;28(3):339-43. doi: 10.4103/0970-9185.98331. [PubMed: 22869941].

50. Wu Y, Liu F, Tang $\mathrm{H}$, Wang $\mathrm{Q}$, Chen $\mathrm{L}$, Wu H, et al. The analgesic efficacy of subcostal transversus abdominis plane block compared with thoracic epidural analgesia and intravenous opioid analgesia after radical gastrectomy. Anesth Analg. 2013;117(2):507-13. doi: 10.1213/ANE.ob013e318297fcee. [PubMed: 23744953].

51. Niraj G, Kelkar A, Jeyapalan I, Graff-Baker P, Williams O, Darbar A, et al. Comparison of analgesic efficacy of subcostal transversus abdominis plane blocks with epidural analgesia following upper abdominal surgery. Anaesthesia. 2011;66(6):465-71. doi: 10.1111/j.13652044.2011.06700.x. [PubMed: 21457153].

52. Niraj G, Kelkar A, Hart E, Horst C, Malik D, Yeow C, et al. Comparison of analgesic efficacy of four-quadrant transversus abdominis plane (TAP) block and continuous posterior TAP analgesia with epidural analgesia in patients undergoing laparoscopic colorectal surgery: an open-label, randomised, non-inferiority trial.Anaesthesia. 2014;69(4):348-55. doi: 10.1111/anae.12546. [PubMed: 24641640].

53. Lee TH, Barrington MJ, Tran TM, Wong D, Hebbard PD. Comparison of extent of sensory block following posterior and subcostal approaches to ultrasound-guided transversus abdominis plane block. Anaesth Intensive Care. 2010;38(3):452-60. [PubMed: 20514952].

54. Bhatia N, Arora S, Jyotsna W, Kaur G. Comparison of posterior and subcostal approaches to ultrasound-guided transverse abdominis plane block for postoperative analgesia in laparoscopic cholecystectomy.JClin Anesth. 2014;26(4):294-9. doi:10.1016/j.jclinane.2013.11.023. [PubMed: 24882606].

55. Shin HJ, Oh AY, Baik JS, Kim JH, Han SH, Hwang JW. Ultrasoundguided oblique subcostal transversus abdominis plane block for analgesia after laparoscopic cholecystectomy: a randomized, controlled, observer-blinded study. Minerva Anestesiol. 2014;80(2):185-93. [PubMed: 24193176].

56. Murouchi T, Yamauchi M, Gi E, Takada Y, Mizuguchi A, Yamakage M, et al. [Ultrasound-guided subcostal and mid-axillary transverus abdominis plane block: a cadaveric study of the spread of injectate]. Masui. 2013;62(1):60-3. [PubMed: 23431895].

57. Rigg JR, Jamrozik K, Myles PS, Silbert BS, Peyton PJ, Parsons RW, et al. Epidural anaesthesia and analgesia and outcome of major surgery: a randomised trial. Lancet. 2002;359(9314):1276-82. doi: 10.1016/S01406736(02)08266-1. [PubMed: 11965272].

58. Basaran B, Basaran A, Kozanhan B, Kasdogan E, Eryilmaz MA, Ozmen $S$. Analgesia and respiratory function after laparoscopic cholecystectomy in patients receiving ultrasound-guided bilateral oblique subcostal transversus abdominis plane block: a randomized doubleblind study. Med Sci Monit. 2015;21:1304-12. doi:10.12659/MSM.893593. [PubMed: 25948166]. 